\title{
Basınçlı Polimer Kompozitlerde Reçine Oranının Mekanik Özelliklere Etkisi
}

\author{
${ }^{* 1}$ Mahmut Bingol and ${ }^{2}$ Kadir Cavdar \\ ${ }^{*}$ Faculty of Engineering, Department of Mechanical Engineering Yalova University, Turkey \\ ${ }^{2}$ Faculty of Engineering, Department of Mechanical Engineering Uludag University, Turkey
}

\begin{abstract}
Özet
Mekanik dayanımın istendiği yerlerde termoset esaslı elyaf takviyeli kompozitler tercih edilmektedir. Kısa çevrim süresi, yüksek mekanik özellikler sağladığı için bir çok alanda SMC kompozit yöntemi yaygın olarak kullanılmaktadır. Bu yöntem ile belli bir formülasyona göre hazırlanan ve pestil olarak isimlendirilen malzemeler olgunlaştırılmak için bir süre bekletildikten sonra basınç ve sıcaklık altında kalıplar içinde istenen şekilde parçalar üretilebilmektedir. Mekanik özellikleri belirleyen en önemli malzeme kullanılan elyafın oranıdır. Bunun dışında kullanılan förmülasyon da önem arz etmektedir.

$\mathrm{Bu}$ çalışmada doymamış polyester oranı değiştirilerek üretilen deney plakaları standart ölçülere göre elmas testerede kesilerek çekme ve eğilme deneyleri yapılmıştır. Daha önce yapılan standart formülasyona göre mekanik özelliklerde oluşan değişim incelenmiştir.
\end{abstract}

Anahtar Kelimeler: Polimer kompozit, Mekanik Özellikler, SMC (Sheet Molding Compound)

\begin{abstract}
Where mechanical strength is required, thermoset-based fiber reinforced composites are preferred. Since it provides short cycle time and high mechanical properties, SMC composite method is widely used in many areas. With this method, the materials that are prepared according to a certain formulation and named as prepreg are kept for a while to maturation, and parts can be produced in molds under pressure and temperature. The most important material determining the mechanical properties is the ratio of the fiber used. Apart from that, the formulation used is also important.
\end{abstract}

In this study, the test plates produced by changing the ratio of unsaturated polyester were cut with a diamond saw according to standard dimensions and tensile and flexural tests were carried out. The change in mechanical properties compared to the previously made standard formulation was examined.

Key words: Polymer Composites, Mechanical Properties, SMC (Sheet Molding Compound)

*Corresponding author: Address: Faculty of Engineering, Department of Mechanical Engineering Yalova University, Yalova TURKEY. E-mail address: mbingol@yalova.edu.tr, Phone: +90226 8156362 


\section{Giriş}

Kompozit malzeme üretiminde kullanılan çok sayıda mühendislik malzemesi mevcuttur. Bunlardan biri olan polimer kompozit malzemeler bazı üstün özelliklerinden dolayı tercih edilmektedir. $\mathrm{Bu}$ malzemelerin üretiminde reçine malzemesi olarak; düşük maliyetli, çoğu malzeme ile uyum sağlayan, hızlı üretime olanak sağlayan, doymamış polyester malzemeler kullanılmaktadır. Kompozit malzemeleri üretmenin, geliştirilmiş-geliştirilen yöntemleri vardır. Basınçlı kalıplama yöntemlerinden biri olan Sheet Molding Compounds (SMC) üretim yönteminde termoset reçine, takviye malzemeleri (elyaflar), dolgular ve katk1 maddeleri olmak üzere 4 ana malzemeden oluşur [1]. İki aşamada üretilen bu yöntemin birinci adımında özel olarak hazırlanan reçine, elyaf, dolgu ve katkı maddeleri bir araya getirilip karıştırılarak pestil (prepreg) biçiminde malzemeler hazırlanır. İkinci adımda da olgunlaşması için bir süre bekletilen pestiller yüksek basınçlı ısıtmalı kalıplarda istenen şekle getirilir [2-3].

SMC üretim aşamalarını başarılı bir şekilde tamamlamak için prosesin hem kimyasal hem de mekanik olarak kontrolünün sağlanması gerekmektedir. Bu da ancak üretim süreci hakkında çok iyi bilgi birikimi olduğunda mümkündür. Örneğin üretim süreci esnasındaki hatalardan dolay1 malzeme yüzeyinde ya da içerisinde boşluk oluşursa bu hem yüzey kalitesini düşürecek aynı zamanda mekanik özelliklerini olumsuz etkileyecektir [4-5]. Yine matris ve elyaf arasındaki etkileşimler ile elyaf oranı ve homojen dağılımı düzgün sağlanamazsa mekanik özellikler ve yüzey kalitesi olumsuz etkilenecektir [5-8]. Üretim süreci uygun şekilde gerçekleştirildiğinde ise üstün nitelikli malzemeler elde edilir. Daha iyi mekanik özellikler, kısa çevrim süresi, mükemmel yüzey kalitesi, estetik, korozyon dayanımı, düşük maliyet gibi özellikler SMC ile üretimin tercih edilmesinin nedenlerinden yalnızca bir kaçıdır. Bu özelliklerinden dolayı özellikle otomotiv sanayiinde saç malzeme yerine kullanımı giderek artmaktadır [4, 9].

Kompozit malzemelerde mukavemeti etkileyen hususlardan biri de malzeme formülasyonudur. $\mathrm{Bu}$ çalışmada SMC kompozit üretim yönteminde kullanılan dolgu maddesi azaltılırken (\%30\%25-\%20) doymamış polyester oranı (R\%35-\%40-\%45) arttırılarak reçine oranının malzeme mukavemetine etkisi incelenmeye çalışılmıştır.

\section{Materyal ve Yöntem}

Basınçlı kalıplama yöntemi olan SMC ile kalıplama sonucu elde edilen nihai ürünün mekanik özellikleri genellikle takviye malzemelerinin cinsine bağlıdır [10] . Reçine oranı ve inert dolgu maddesi ağırlık oranı olarak Tablo 1.' de gösterildiği gibi değiştirilerek kompozit malzemeler elde edilmiştir. İki aşamada üretilen SMC kompozitlerin ilk aşamasında pestil biçimindeki malzemeler bir miktar bekletilerek olgunlaştırılır.

Tablo 1. Dokuma cam elyaf pestil için kullanılan formülasyon

\begin{tabular}{lc}
\multicolumn{1}{c}{ Malzeme } & Ağırlıkça (\%) \\
\hline Doymamış Polyester (Polipol 347) & $35-40-45$ \\
İnert Dolgu (CaCO3) Kalsit & $30-25-20$
\end{tabular}


Termoplastik Reçine $\quad 10$

Polimerizasyon Katalisti $\quad 0,5$

İç Kalıp Ayırııı Zn-Çinko Stearat

Diğer katkılar $\quad 3,2$

Dokuma Cam Elyaf $\quad 20$

\begin{tabular}{ll} 
Toplam & 100 \\
\hline
\end{tabular}

Bu çalışmada Poliya A.Ş. Türkiye firmasından temin edilen ve SMC kalıplama yöntemi için özel olarak üretilmiş Polipol-347 SMC-BMC tip doymamış polyester kullanılmıştır. Kesikli (kırpılmış) elde etmek için Cam Elyaf A.Ş. Türkiye‘den SMC yöntemine uygun olan -SMC-3 çok uçlu fitil cam elyaf bobin temin edilmiştir.

$\mathrm{Bu}$ formülasyona göre hazırlanan pestiller bir süre olgunlaştırılmak üzere bekletildikten sonra SMC kalıp içerisine yerleştirilerek, $140-150^{\circ} \mathrm{C}$ sıcaklık ve uygun basınç altında işlenerek deney plakaları elde edilmiştir. Üretilen bu plakalar, çekme deneyi numunesi için ISO 527, eğilme deneyi numunesi için ise ISO 178 standartlarına uygun şekilde kesilerek test edilmiştir.

\section{Sonuçlar}

Elyaflı kompozit malzemeler genellikle iki ana bileşenden oluşmaktadır bunlar; takviye malzemeleri (elyaflar) ve bu malzemeleri bir arada tutan matris malzeme. Matris tek bir malzemeden oluşabildiği gibi ek olarak katkı maddeleri de içerebilmektedir. Takviye malzemeleri mukavemetini etkileyen en önemli malzeme olmasına rağmen matris malzeme içerisinde yapılabilecek değişikliklerin de mukavemete etkisi olmaktadır. Farklı oranlarda üretilen deney numuneleri standartlara uygun olarak çekme ve eğilme testlerine tabi tutulduktan sonra elde edilen sonuçlar Tablo 2. ve Şekil 1.' de verilmiştir.

Tablo 2. Farklı reçine oranlı SMC numunelerin ortalama çekme ve eğilme deneyi sonuçları

\begin{tabular}{|c|c|c|}
\hline Reçine oranı* & $\begin{array}{l}\text { Çekme gerilmesi } \\
\mathrm{N} / \mathbf{m m}^{2}(\mathrm{MPa})\end{array}$ & $\begin{array}{c}\text { Eğilme gerilmesi } \\
\text { N/mm² (MPa) }\end{array}$ \\
\hline SMC-R\%35 & 67,584 & 153,49 \\
\hline SMC-R\% $\%$ & 72,715 & 164,19 \\
\hline SMC-R\%45 & 65,07 & 149,84 \\
\hline
\end{tabular}

*Tüm sonuçların ortalama değerleri verilmiştir

SMC kompozitlerde dolgu maddesi maliyeti azaltmanın yanında pestilin viskozitesini arttırmak içinde kullanılır. Böylelikle kıvam kazanan pestil basınç altında daha iyi kalıplanabilmektedir [11]. Tablo 2.' ve Şekil 1.' de verilen sonuçlar incelendiğinde reçine oranı \%35' den \%40'a 
yükseldiğinde, dolgu maddesi değeri ise \%30'dan \%25'e azaldığında; çekme gerilmesi değeri yaklaşık \%8, eğilme gerilmesi değeri \%7 oranında artmıştır. Buna rağmen reçine oranı \%35' den \%45' e yükseldiğinde, dolgu maddesi değeri ise \%30' dan \%20' ye azaldığında; çekme ve eğilme gerilmesi değerinin yükselmesi beklenirken daha da düşmüştür.
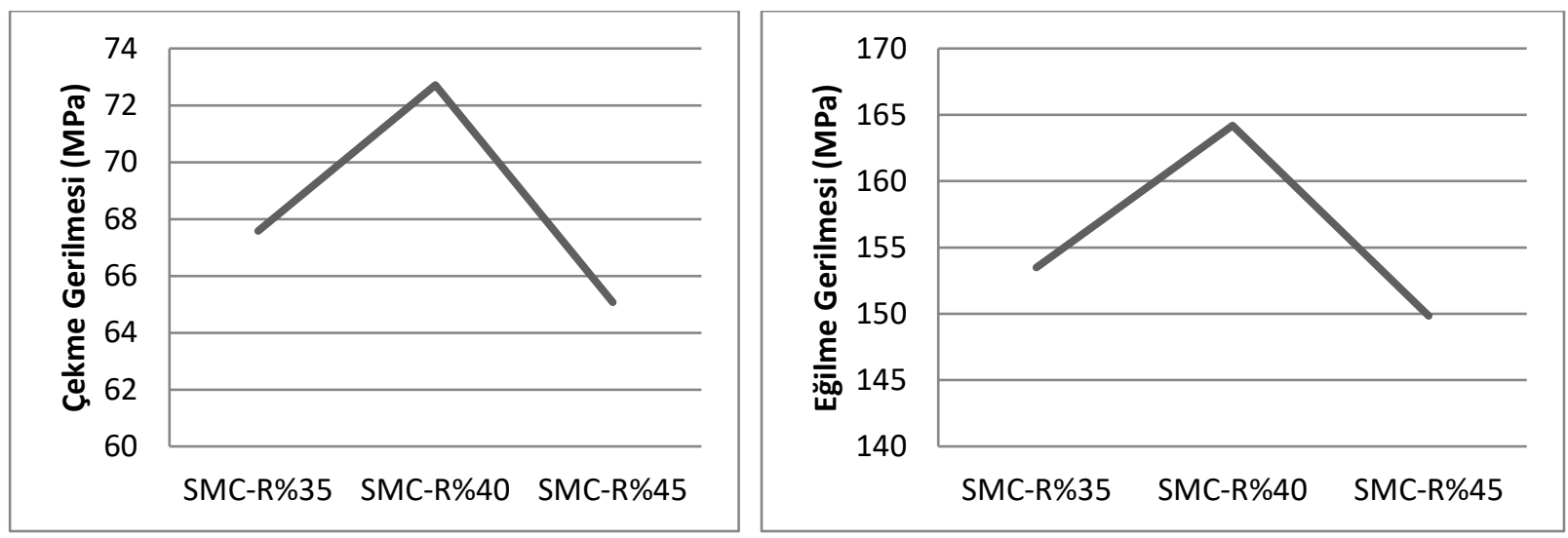

Şekil 1. Farklı reçine oranlı SMC numunelerin ortalama çekme ve eğilme deneyi sonuçları

Bunun sebebi viskozitesi azalan SMC pestil basınçlı kalıba konulduğunda daha fazla malzeme kalıp kenarlarında boşluklardan taşmaktadır. Sonuç olarak kompozit malzeme içerisinde hem boşluklu poroz yapılar hem de elyaf ve matris arasında boşluklar oluşmaktadır. Bu da malzeme mukavemetini beklenenin tersi yönünde azaltmaktadır [4-6]. Aynı zamanda bu boşluklar malzeme üzerinde matris çatlaklarına sebep olarak küçük gerilme etkilerinde malzemenin hasara uğramasına neden olur. Elyaf oranı düşük ve ara yüzey bağları zayıf olan numuneler de çok düşük kuvvetlerde belli bir yerinden kırılma eğilimindedirler [12].

\section{Tartışma ve Sonuçlar}

Kompozit malzemelerin mekanik özelliklerini etkileyen çok sayıda parametre mevcuttur. Bunlardan bazıları; kullanılan malzemeler, bu malzemelerin oranları, üretim yöntemleri olarak sıralanabilir. Polimer kompozitlerde kullanılan elyafları bir arada tutun matris malzeme içindeki ana yapıştırıcı malzeme reçinedir. Dolgu maddesi olarak kullanılan malzemeler genellikle maliyet azaltmak için kullanılmaktadır. SMC basınçlı bir üretim yöntemi olduğu için dolgu maddesinin ayrıca viskozite arttırıcı görevi de vardır. Diğer kompozit üretim yöntemlerinde reçinenin artması ve dolgu maddesinin azalması mekanik özellikleri doğru orantılı olarak arttırırken SMC yönteminde belli bir orana kadar arttırmaktadır. Elde edilen sonuçlara göre reçine oranı yaklaşık \%40, dolgu madde oranı yaklaşı \%25'e kadar mekanik özelliklerde nispeten olumlu sonuç verirken; reçine oran $1 \% 45$ 'e çıkmasına rağmen dolgu oranı \%20' ye azaldığında mekanik özelliklerde beklenenin aksine azalma olmaktadır. Bunun sebebi olarak basınçla kalıplanan SMC kompozit malzeme üretiminde, kalıba konulan SMC pestilin 
viskozitesinin azalması bunun sonucu kalıp boşluğundan fazla malzeme dışarı taşması gerçekleşmektedir. Neticede kompozit parça içinde boşluklu yapı oluşmakta aynı zamanda reçine ile matris arasında ara yüzey yapışması zayıflamakta bunun sonucu mekanik özellikler azalmaktadir.

\section{Kaynaklar}

[1] Kia, H.G., Sheet Molding Compound Materials: Science \& Technology. Hanser Gardner Pubns. Ohio USA; 1993, 257 pp.

[2] Rosato, D.V., Rosato, D.V. Chapter 4 - Compound constructions. Reinforced Plastics Handbook (Third Edition). Amsterdam, Elsevier Science; 2005, 212-253.

[3] van Voorn, B., Smit, H.H.G., Sinke, R.J., de Klerk, B. Natural fibre reinforced sheet moulding compound. Composites Part A: Applied Science and Manufacturing; 2001, 32: 12711279.

[4] Merle, G., Allemand, J., Camino, G., Luda, M.P., Revellino, M., Blancon, R., Morphology analysis of microvoids in SMC: ageing effects. Composites Part A: Applied Science and Manufacturing ; 1998, 29: 1535-1543.

[5] Le, T.H., Dumont, P.J.J., Orgéas, L., Favier, D., Salvo, L., Boller, E. X-ray phase contrast microtomography for the analysis of the fibrous microstructure of SMC composites. Composites Part A: Applied Science and Manufacturing ; 2008, 39: 91-103.

[6] Feuillade, V., Bergeret, A., Quantin, J.C., Crespy, A., Relationships between the glass fibre sizing composition and the surface quality of sheet moulding compounds (SMC) body panels. Composites Science and Technology ; 2006, 66: 115-127.

[7] Jendli, Z., Meraghni, F., Fitoussi, J., Baptiste, D. Micromechanical analysis of strain rate effect on damage evolution in sheet molding compound composites. Composites Part A: Applied Science and Manufacturing ; 2004, 35: 779-785.

[8] Kim, M.-S., Lee, W.I., Han, W.-S., Vautrin, A. Optimisation of location and dimension of SMC precharge in compression moulding process. Computers \& Structures ; 2011, 89: 15231534.

[9] Tatara, R.A. 17 - Compression Molding A2 - Kutz, Myer. Applied Plastics Engineering Handbook. Oxford, William Andrew Publishing; 2011, 289-309.

[10] Bingöl M., Cavdar K. New investigations on higher mechanical properties of woven glass fiber reinforced SMC composites. Indian Journal of Engineering \& Materials Sciences; 2018, Vol. 25, August 2018, 315-320 pp. 
[11] Orgéas, L., Dumont, P.J.J., Sheet Molding Compounds, Wiley Encyclopedia of Composites ; 2012, 2683-2718

[12] Bingöl M., Cavdar K. Dokuma Cam Elyafların Farklı Katlarının SMC Kompozitlerin Mekanik Özelliklerine Etkisinin İncelenmesi. 5. International Polymeric Composite Symposium and Workshops; 2017. 